DOI: http://doi.org/10.21698/simi.2018.fp46

\title{
HEAVY METALS EMISSIONS TO AIR FROM INDUSTRIAL PLANTS: CRITICALITIES AND SOLUTIONS
}

\author{
Elena Cristina Rada
}

University of Insubria, Department of Theoretical and Applied Sciences, via G.B. Vico 46, 21100 Varese, elena.rada@uninsubria.it, Italy

\begin{abstract}
In the European Union, the regulation in the sector of emissions into the atmosphere from industrial plants did not evolve homogeneously. As demonstrated in this article, the sector of waste to energy plants has shown important improvements in the latest 20 years, whilst other industrial plants were subject to less stringent regulations. As consequence, the human exposure resulting from industrial plant authorisations depend on the plant to be authorised. Examples of consequent inequalities and related criticalities concern both macro and micro-pollutants. The present article concerns a category of micro-pollutants: heavy metals emissions into the atmosphere. The sector of thermo-chemical treatment of waste is presently analysed in details in the University of Insubria in the frame of a research in progress. The present article refers to some aspects emerged in that research and integrates them by a preliminary analysis of the underestimated criticalities of other industrial sectors. In both cases, the core of the problem is the demonstrable excessive simplification of the control of heavy metals emissions. Large industrial plants are controlled through an approach that does not exploit in details the available information of toxic effects of each heavy metal. Small industrial plants can be subject to simple authorisations with no analysis of the local impact of their emissions. In both cases, secondary and diffused emissions can have an impact higher than the conveyed ones, as discussed in this article. A methodology of control that integrates the present regulation, avoiding under-estimated human exposures to heavy metals is mandatory.
\end{abstract}

Keywords: emissions, industrial plants, heavy metals, health, regulation

\section{Introduction}

The European Union (EU) regulation for emissions into the atmosphere from industrial plants did not show a homogeneous evolution in the recent decades. The sector of waste to energy (specifically of thermo-chemical plants) showed a clear improvement in the environmental performances of the authorised plants thanks to an approach more sensible to the reduction of the human exposure to emitted atmospheric pollutants. Other industrial sectors were not subject to the same restrictions in spite of potential high impacts, as explained below.

An example is the case of NOx. A cement factory must comply with an emission concentration at the stack that may be even one order of magnitude higher than the one of an incinerator. Moreover, the flowrate of a cement factory could be even one order of magnitude higher than the one of an incinerator. Thus, the load of NOx emitted from the stack of a cement factory could be even two orders of magnitude higher than the load released from an incinerator. Supposing the same characteristics 


\section{INTERNATIONAL SYMPOSIUM "THE ENVIRONMENT AND THE INDUSTRY", SIMI 2018, PROCEEDINGS BOOK}

of release into the atmosphere (stack height, off-gas temperature, off-gas velocity, same site) the consequent incidence on the air quality at ground level can change of two orders of magnitude.

Examples like this one, of consequent inequalities and potential criticalities, can be seen not only for macro-pollutants like NOx but also for micro-pollutants. The present article concerns a specific category of micro-pollutants: it concerns heavy metals emissions into the atmosphere. The core of the problem analysed in the present article is the demonstrable excessive simplification of the control of heavy metals emissions in some industrial plants.

Readers of scientific journals could have caught some concerns on the management of the risk from heavy metals emitted into the atmosphere from industrial plants. The concern on this topic is clear in China as demonstrated by the visible presence of Chinese authors in the Scopus database on this subject. In China, regulation and control organisation in the sector of environment are not yet developed like in EU, thus the present criticalities could be expected. A question remains on the criticalities present in the EU for under-estimation of the role of heavy metals. The present article demonstrates that some criticalities are still present in the EU in spite of a modern regulation.

\section{Materials and Methods}

The sector of industrial plants can be divided in two sub-sectors: waste to energy plants (the ones not related to biogas production) and other industrial plants involved in heavy metals release into the atmosphere.

For both the sub-sectors, a link among case studies of interest was sought in order to make more understandable the criticalities to be pointed out. In order to do that, international databases were analysed containing proceedings papers and scientific journal articles. Additional analyses concerned the literature not related to the most known databases. Indeed by this way specific charactarisations of the environment and the stack emissions may be found in technical documentation.

In order to consider relevant a case study, not only the concentrations of the emissions at the stack of a plant were taken into account. Indeed the human exposure to persistent atmospheric pollutants like heavy metals depend on many factors (the following list reports only the main ones):

- Emitted load (obtained multiplying the flow-rate and the concentration);

- Dynamics of the emissions (cyclic, 24/24h etc.);

- Stack height of the conveyed emissions;

- Off-gas temperature at the stack;

- Off-gas velocity at the stack;

- Secondary emissions characteristics;

- Diffused emissions characteristics;

- Meteorologic parameters specific for the site of the plant;

- Toxicological characteristics of each heavy metal emitted.

Considering this last point, data on the toxicity of each compound are available in form of Cancer Slope Factor (SF) for the carcinogenic substances. SF, expressed in ( $\left.\mathrm{mg} \mathrm{kgbw}^{-1} \mathrm{~d}^{-1}\right)^{-1}$ where "bw" means body weight, is defined as the incremental cancer risk associated with a unit dose of a carcinogen. It is the slope of the curve representing the relationship between dose and cancer risk. Depending on the 


\section{INTERNATIONAL SYMPOSIUM "THE ENVIRONMENT AND THE INDUSTRY", SIMI 2018, PROCEEDINGS BOOK}

exposure pathway, inhalation or ingestion, we distinguish between $\mathrm{SF}_{\text {inhal }}$ and $\mathrm{SF}_{\text {oral }}$. Table 1 reports the toxicologic parameters available for the considered pollutants.

Table 1 - Toxicologic characteristics of the considered pollutants

\begin{tabular}{c|c|c}
\hline & $\mathrm{SF}_{\text {inhal }}$ & $\mathrm{SF}_{\text {oral }}$ \\
Cadmium & {$\left[\left(\mathrm{mg} \mathrm{kg}_{\mathrm{bw}}^{-1} \mathrm{~d}^{-1}\right)^{-1}\right]$} & {$\left[\left(\mathrm{mg} \mathrm{kg}_{\mathrm{bw}}^{-1} \mathrm{~d}^{-1}\right)^{-1}\right]$} \\
Tallium & $6.30 \mathrm{E}+00$ & - \\
Arsenic & - & - \\
Chromium III & $1.50 \mathrm{E}+00$ & $1.50 \mathrm{E}+00$ \\
Chromium VI & - & - \\
Nickel & $2.94 \mathrm{E}+02$ & - \\
\hline
\end{tabular}

From Table 1 we can remark that (Rada 2018):

- Heavy metals show SFs in a range of two orders of magnitude.

- In spite of that, the regulation in force sums heavy metal concentrations with no regard to their specific toxicity; as examples:

- in the regulation for incineration emissions at the stack, $C d+T_{1}$ are summed even if only one has a SF;

- arsenic, chromium and nickel are summed with other six heavy metals even if only three have a SF.

Just to understand the complexity of the sector, planst like the steel making ones are characterised by conveyed, secondary and diffused emissions.

It is clear that a plant constructed in a near-desert area has a very limited impact on the health of the population. The analysis presented in this article considers the criticalities as related to a densely populated areas.

\section{Results and Discussion}

Two links have been found among the case studies selected from the literature:

- $\mathrm{Cr}^{\mathrm{VI}}$ emissions as demonstration of the no optimised approach for the management of heavy metals from industrial stacks; additional details on this issue can be found in (Rada 2018).

- Low height emissions of heavy metals into the atmosphere.

In the case of residual municipal solid waste (RMSW) and special waste incinerators, supposing to consider a limit value of $\mathrm{Cd}$ at the stack as $50 \mu \mathrm{g} / \mathrm{Nm}^{3}$, it is easy to understand that for $\mathrm{Cr}^{\mathrm{VI}}$, carcinogenic, the emission at the stack must be coherent with what requested for $\mathrm{Cd}$. In spite of that, the regulation in force asks for $\mathrm{Cr}$ only the value of $\mathrm{Cr}_{\text {tot }}$. Its value must be considered in the frame of a sum with other heavy metals. Taking into account the different carcinogenicity of $\mathrm{Cr}^{\mathrm{VI}}$, along the pathway adopted to authorize the emissions of an Italian plant (PAT 2009) it was proposed a maximum value of $\mathrm{Cr}^{\mathrm{VI}}$ to be guaranteed at the stack. The proposed value was $1 \mu \mathrm{g} / \mathrm{Nm}^{3}$ calculated on yearly basis (being a carcinogenic compound, its relevance is on a long period of exposure) (PAT 2009). It is an approach that even 10 years ago recognized the limits of the regulation in force for the sector. However, no one focused in details on the matter of the equivalent impact given by different carcinogenic compounds.

Concerning tannery sludge and its thermochemical treatment, two big leathertanning industrial areas are present in Italy. Since long time, the attention was put on the role of Chromium. It is used as $\mathrm{Cr}^{\mathrm{III}}$ in the tanning activities. The potential risk depends on two main reasons (Rada 2018): 


\section{INTERNATIONAL SYMPOSIUM "THE ENVIRONMENT AND THE INDUSTRY", SIMI 2018, PROCEEDINGS BOOK}

- It can be found in trace in the leather product, causing allergic reactions; that limits also the possibility of the reuse of the material;

- It is transformed into $\mathrm{Cr}^{\mathrm{VI}}$ if the final treatment of the generated sludge (from wastewater treatment plants) if based on oxidative conditions; that limits the energy recovery from this sludge in spite of the fact that it is assimilated to a discarded biomass, thus being a renewable source of energy.

In order to find a solution, the Italian Authorities promoted and financed many researches on this topic. What emerges from the analysis of role of $\mathrm{Cr}^{\mathrm{VI}}$ emission in this sector, is the inadequacy of the regulation on emissions to air: the high content of $\mathrm{Cr}^{\mathrm{III}}$ in sludge can cause high concentrations of $\mathrm{Cr}^{\mathrm{VI}}$ at the stack in case of combustion, with no problems in complying the national regulation on heavy metals emissions. Just to have an example, a concentration of $\mathrm{Cr}^{\mathrm{VI}}$ equal to $100 \mu \mathrm{g} / \mathrm{Nm}^{3}$ and the rest of the heavy metals equal to $400 \mu \mathrm{g} / \mathrm{Nm}^{3}$ results acceptable from the regulation even if the health risk only from $\mathrm{Cr}^{\mathrm{VI}}$ results significantly higher than the risk from PCDD/F assumed equal to the limit (0.1 ngTEQ/ $\mathrm{Nm}^{3}$ ) (Rada 2018).

The problem cannot be not avoided in full in the case of gasification: a local formation of $\mathrm{Cr}^{\mathrm{VI}}$ can be found for local oxidizing conditions, even if the global conditions in terms of free Oxygen availability are sub-stoichiometric. Pyrolysis is worst: the combustion of the produced char (the solid output of the plant) offers to $\mathrm{Cr}^{\mathrm{III}}$ there contained the possibility to be oxidized to $\mathrm{Cr}^{\mathrm{VI}}$. At the end, an important solution is prevention: tanning without $\mathrm{Cr}$ (called wet white leather) is a growing reality in the sector; however long time is needed to get a full conversion of the approach because of higher costs compared to the use of $\mathrm{Cr}^{\mathrm{III}}$. It is clear that an integration of the regulatory approach is compulsory.

Woody waste combustion can find problems from $\mathrm{Cr}^{\mathrm{VI}}$. In the latest years, EU has started a review of the regulations on combustion of woody biomass. In Italy, virgin wood belongs to the category of fuels. Treated wood even if derived from woodfurniture industry rejects is considered as waste. That has consequences on the option of combustion: its combustion is subject to more stringent requests (in term of process monitoring and emission limit). A question debated recently in Italy concerned the possibility to classify slightly treated wood as fuel. A research was developed and analyses before and after combustion (on pilot scale) were made, dealing with organic micropollutants (Passamani et al 2017) and heavy metals (but not detailing on $\mathrm{Cr}^{\mathrm{VI}}$ ). What is interesting for the present paper is the analysis of the heavy metals content in virgin wood. If the supplied wood comes from a polluted land, an anomalous heavy metals amount ( $\mathrm{Cr}$ included) can enters a burner without any control of its emissions. This problem, not yet analysed in Italy, is clear in Germany: there, some limits are set. In this case, the approach of Germany could become a reference for other countries where no control on wood composition is requested. However, the problem remains in case treated wood were burnt because its Cr content usually is not characterized.

Concerning the case of special waste gasification, a recent proposal (gasification followed by immediate combustion of the generated syngas) has been put forward in the Italy (Appa 2018). Also in this case, the authorization pathway suffers from the aggregation of heavy metals in the limit values to be complied with at the stack:

- The sum of Cd and $\mathrm{Tl}$ has a limit with no consideration of each toxicologic characteristic; 


\section{INTERNATIONAL SYMPOSIUM "THE ENVIRONMENT AND THE INDUSTRY", SIMI 2018, PROCEEDINGS BOOK}

- The sum of antimonium, arsenic, lead, total chromium, cobalt, manganese, nickel e vanadium $(\mathrm{Sb}+\mathrm{As}+\mathrm{Cr}+\mathrm{Pb}+\mathrm{Co}+\mathrm{Cu}+\mathrm{Mn}+\mathrm{Ni}+\mathrm{V})$ has a limit, again with no specific attention to the toxicologic effects of each pollutant.

Dispersion modeling and assumptions on the potential presence of $\mathrm{Cr}^{\mathrm{VI}}$ demonstrated that this heavy metal can be the dominant pollutant in the health impact of a plant, higher than the impact of dioxins and furans (PCDD/F) (Rada 2018). In spite of that, this result is not taken into account by the regulation in force as the value of $\mathrm{Cr}^{\mathrm{VI}}$ is not known as not requested in the analytical characterization.

The sector of SRF (Secondary Refused Fuel) may have potential problems from $\mathrm{Cr}^{\mathrm{VI}}$ emissions. This criticality is demonstrated by a few cases in the sector of cement works. There, some plants are authorized for co-combustion of special waste. An interesting case is the one of an Italian cement factory (Province of Como 2017) where SRF and sewage sludge (after thermal drying) are authorized for cocombustion. An attention to the underlined problem is demonstrated by the fact that those fuels are accepted at the gate of the plant only if they comply with limits of some pollutants including total Chromium and $\mathrm{Cr}^{\mathrm{VI}}$.

Small painting works and small printing activities can be authorised with a release at the stack that could give a local impact higher than the one of an incinerator. That is demonstrated in a recent study (Appa 2018). In the case of painting activities, it was demonstrated that closing a painting plant to give an adequate area to a modern gasifier may allow a reduction of the local impact of $\mathrm{Cr}^{\mathrm{VI}}$ (referring to the authorized values). That is the consequence of the fact that small activities are authorized to emit at low height with a consequent (often not estimated) limitation of the dilution capability of the pollutants released. After analysing the complexity of the link (among case studies) offered by $\mathrm{Cr}^{\mathrm{VI}}$, another overview of criticalities, linked by the way of release, was studied. To this concern, it can be pointed out that steel making plants are characterised by secondary and diffused emissions that could create a significant local impact even if the conveyed emissions are managed with the best available technologies. Indeed, the main stack is the only kind of emission that can be monitored with a high detail. Unexpected potential emissions could come also from bio-mechanical plants of RMSW. The problem could be related to the biofilter that is often used to manage the emissions from the biological process. The height of the biofilter is around $2 \mathrm{~m}$. The temperature of release is around the room temperature. The hydraulic load of release is around $100 \mathrm{~m} / \mathrm{h}$. As a consequence the dilution is reduced. Until now, no criticality has been pointed out in the literature (only few data were produced in Austria and Germany about 20 years ago, generally not published in scientific papers). The produced values showed generally a high variability. What was not analysed in that period is the risk associated to the local contribution of the plant from the point of view of heavy metals. Indeed, a release of one order of magnitude higher than a background value could be associated to an individual health risk higher than $10^{-6}$.

Taking into account what found in the discussed case studies, an enhanced approach to take $\mathrm{Cr}^{\mathrm{VI}}$ impact under control is compulsory. A recent proposal focuses on it (Rada 2018). The steps are:

- Ask for total Cr values at the stack from the laboratories involved in emission characterization (avoiding receiving only sum of multiple heavy metals) 


\section{INTERNATIONAL SYMPOSIUM "THE ENVIRONMENT AND THE INDUSTRY", SIMI 2018, PROCEEDINGS BOOK}

- Set a preliminary threshold for total Cr (taking into account comparatively the toxicity of the other pollutants emitted and the typical ratio $\mathrm{Cr} r^{\mathrm{VI}} /$ total $\mathrm{Cr}$ in the sector) so that, when total $\mathrm{Cr}$ analyses result beyond it:

- specific analyses of $\mathrm{Cr}^{\mathrm{VI}}$ will be performed (case specific) in addition to total $\mathrm{Cr}$ analyses

- a risk analysis will be developed in order to verify if a different threshold set for the total Cr emissions at the stack must be introduced

It is clear that in case the plant is already authorised, the collaboration of the company managing it is compulsory.

Moreover, the focus on the role of $\mathrm{Cr}^{\mathrm{VI}}$ in specific contexts shown in this article should be extended to other heavy metals.

\section{Conclusions}

The presented overview on the role of heavy metals in the industrial sector (concerning their emissions into the atmosphere) demonstrates that their potential impact may be underestimated.

That depends on a too simplified regulation that does not valorize the results of the toxicological studies on heavy metals characteristics. The simplification is so hight that, for the case of one of the most carcinogenic compounds, $\mathrm{Cr}^{\mathrm{VI}}$ no analyses must be made according to the regulation in force.

This simplification causes an anomaly in the EU approach as some inequalities in the human exposure can be created. Solutions should be made integrating the regulation in force with additional methodologies of emission characterisation based on the valorisation of the toxicological information available for each heavy metal.

An additional problem can come from the way of release into the atmosphere. Indeed, in case of low height releases, secondary emissions and diffused emissions, the reduced dilution can cause an accumulation of heavy metals in the surroundings of the plant.

\section{References}

APPA-Provincia autonoma di Balzano, 2018. Available from: http://ambiente.provincia.bz.it/valutazioni-ambientali/archivio-procedure-viavas-screening-aia.asp.[12 July 2018]. In Italian.

Passamani, G, Rada, EC, Tirler, W, Tava, M, Torretta, V \& Ragazzi, M 2017, 'PCDD/F emissions from virgin and treated wood combustion', International Journal of Energy Production and Management, vol. 2, no. 1, pp. 17-27.

Rada, EC 2018, 'Special waste valorisation and renewable energy generation under a circular economy: which priorities', 3rd International Conference on Energy Production and Management: The Quest for Sustainable Energy, 10-12 September 2018, New Forest, UK.

PAT 2009, Studio di Fattibilità, 'Concessione di lavori per la progettazione, realizzazione e gestione dell'impianto di combustione o altro trattamento termico con recupero energetico per rifiuti urbani e speciali assimilabili in località Ischia Podetti, nel Comune di Trento', (Feasibility Sudy-combustion plant or based on other thermal process with energy recovery for MSW and special assimilable waste), Authonomous Province of Trento. [June 2009]. In Italian. 